\title{
Evaluation of deep drawing force under different friction conditions
}

\author{
Lucian Lăzărescu ${ }^{1, *}$, and Dorel Banabic ${ }^{1}$ \\ ${ }^{1}$ Technical University of Cluj-Napoca, CERTETA Research Centre, B-dul Muncii nr. 103-105, Cluj- \\ Napoca, Romania
}

\begin{abstract}
The purpose of this study is to investigate the variation of the required punch load during the deep drawing process under different friction conditions. In this regards, several deep-drawing tests of cylindrical cups were conducted under four friction conditions at the toolblank interface. The first case was the dry deep-drawing, considered as a reference friction condition, while in the other three cases hydraulic oil, lithium-based grease and animal fat were used as lubricants. For each friction case, three levels of blank holding force were adopted, namely 10 , 20 and $25 \mathrm{kN}$. The finite element simulation of the deep-drawing process was used to generate a set of calibration curves. By overlapping the experimental load-stroke curves on the calibration curves, the friction coefficient was estimated for each friction case.
\end{abstract}

\section{Introduction}

Deep-drawing is one of the most used forming methods with a wide range of applications in different fields such as automotive and aerospace industries. In this process a sheet metal is transformed into a hollow part by means of forming tools whose geometry is consistent with the shape of the part. There are several process variables that influence the success of a deep-drawing process. These include the blank-holding force (BHF) and the friction between tools and blank.

In recent years, some research works have been conducted to study the influence of friction conditions and BHF on the deep-drawing process. Ahmetoglu et al. [1] consider that BHF is the major factor affecting the occurrence of defects. Padmanabhan et al. [2] used FEM and Taguchi technique to determine the relative influence of die radius, blankholding force and friction coefficient on the punch load. They have found that the die radius has a major influence followed by friction coefficient and BHF. Raju et al. [3], also conducted a study using the Taguchi method and their results have revealed that the die shoulder radius has a major influence on the thickness distribution of the deep-drawn cups made from AA 6061 aluminum alloy sheet, followed by BHF and punch nose radius. Browne et al. [4] have investigated the effects of many factors, including lubrication type and blank-holding pressure, on the punch load using Taguchi's L8(27) orthogonal array. Their results have shown that the friction is one of the parameters that have the greatest

\footnotetext{
*Corresponding author: lucian.lazarescu@,tcm.utcluj.ro
} 
influence on punch load. The authors of the paper [5] have studied the effect of die radius, surface roughness of the tools, drawing speed, blank-holding force, and lubrication type on dynamic friction coefficient between the flange and fillet regions of the tools and sheet metal by using the ANOVA method. Their results have proved that the lubricant type is an effective parameter for the flange and fillet regions.

Deep-drawing is also regarded as a laboratory test that can be used to assess the lubricant performance [6-9]. According to [7] the lower is the punch force, the better is the lubricant.

The above literature review shows that friction at the tool-blank interface and BHF are two important parameters and there are few studies that analyses the influence of friction conditions combined with the effect of BHF on the punch force.

The current study investigates the relationship between the punch force and friction conditions at the tool-blank interface in combination with the effect of bank-holding force in the deep-drawing process of cylindrical cups.

\section{Experiments}

\subsection{Material and lubricants}

A DC04 cold rolled steel sheet with the nominal thickness of $0.85 \mathrm{~mm}$ was used to perform the experiments in this study. The main mechanical properties of DC04 material are listed in Table 1. The values of the yield stress and the Lankford coefficient were obtained by tensile tests performed on specimens cut from the metal sheet at different orientations with respect to the rolling direction: 0,45 and $90^{\circ}$. A tensile testing machine Zwick Roell Z150 was used to perform the tests. The parameters of Swift's hardening law were identified by fitting the experimental true stress-true plastic strain curve by equation 1 . The data listed in Table 1 is used to describe the mechanical behavior of the blank in the finite element simulation of the deep-drawing process, as described in Chapter 3:

$$
\sigma=K\left(\varepsilon_{0}+\varepsilon_{p}\right)^{n}
$$

where $\sigma$ is the flow stress and $\varepsilon_{\mathrm{p}}$ is the plastic strain.

The lubricants used in experiments were hydraulic oil (HLP 46), lithium-based grease (Repsol Grasa Mobilgras EP 2), and animal grease provided by the Erichsen Company, Germany.

Table 1. Mechanical properties of DC04 steel sheet (thickness $0.85 \mathrm{~mm}$ ).

\begin{tabular}{|c|c|c|c|c|}
\hline \multirow{2}{*}{\multicolumn{2}{|c|}{ Parameter }} & \multicolumn{3}{|c|}{ Value at different specimen orientations } \\
\hline & & $0^{\circ}$ & $45^{\circ}$ & $90^{\circ}$ \\
\hline \multicolumn{2}{|c|}{ Yield stress, $R_{p 0.2}[\mathrm{MPa}]$} & 196 & 211 & 206 \\
\hline \multicolumn{2}{|c|}{ Lankford parameter, $r[-]$} & 1.96 & 1.30 & 2.19 \\
\hline \multicolumn{2}{|c|}{ Young's Modulus, $E[\mathrm{MPa}]$} & \multicolumn{3}{|c|}{207000} \\
\hline \multicolumn{2}{|c|}{ Poisson's ratio, $v[-]$} & \multicolumn{3}{|c|}{0.28} \\
\hline \multicolumn{2}{|c|}{ Mass density $\rho\left[\mathrm{kg} / \mathrm{m}^{3}\right]$} & \multicolumn{3}{|c|}{7800} \\
\hline \multirow{3}{*}{$\begin{array}{l}\text { Coefficients of } \\
\text { Swift's } \\
\text { hardening law }\end{array}$} & Strength coefficient, $K[\mathrm{MPa}]$ & \multicolumn{3}{|c|}{546.5} \\
\hline & Strain hardening coefficient, $n[-]$ & \multicolumn{3}{|c|}{0.239} \\
\hline & Initial yield strain, $\varepsilon_{0}[-]$ & \multicolumn{3}{|c|}{0.009} \\
\hline
\end{tabular}




\subsection{Experimental equipment}

The deep-drawing of cylindrical cups was performed on a universal sheet metal testing machine (Erichsen type). Figure 1 shows the main dimensions of the tools and the components of the deep-drawing device.

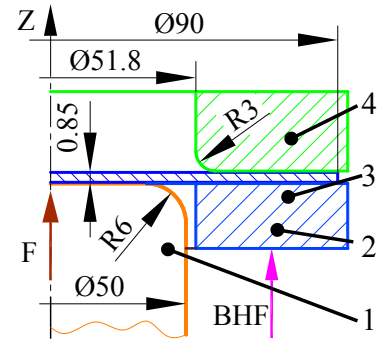

a)

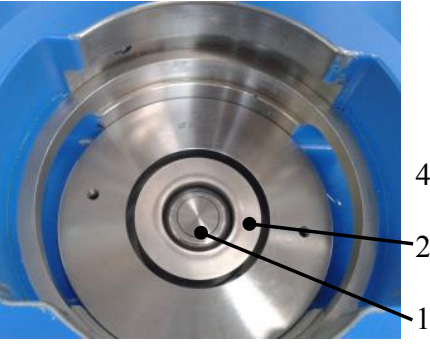

b)

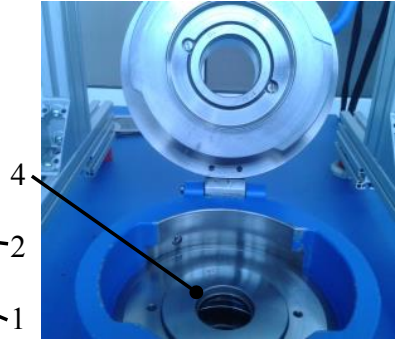

c)

Fig. 1. Deep-drawing tools: a) - tool dimensions; b) and c) - universal sheet metal testing machine (Erichsen type); 1 - punch; 2 - blank holder; 3 - blank; 4 - die.

The punch is placed under the blank and is movable, while the die and the blank holder are stationary. The blank diameter is $90 \mathrm{~mm}$; the punch and die diameters are 50 and $51.8 \mathrm{~mm}$, respectively. The die and punch fillet radii of 3 and $6 \mathrm{~mm}$, respectively, were selected to perform the experiments. The punch force and the punch stroke were continuously recorded by the machine software.

\subsection{Experimental conditions}

In order to investigate the evolution of the punch force during the deep-drawing process under different friction conditions (FC) at the tool-blank interface, four friction cases were considered: FC1 - deep-drawing without lubricant; FC2 - use of hydraulic oil; FC3 - use of a lithium-based grease, and FC4 - use of a lubricant based animal grease. These four cases of friction conditions were combined with three levels of the blank-holding force: 10, 20 and $25 \mathrm{kN}$, respectively. Before starting each individual test, the tools and the blank were cleaned using alcohol, after which a new lubricant was applied. Twelve different experimental conditions were considered, as a result of combining four friction conditions and three levels of the blank-holding force. Figure 2 shows cups drawn in different combinations of friction conditions and blank-holding forces.

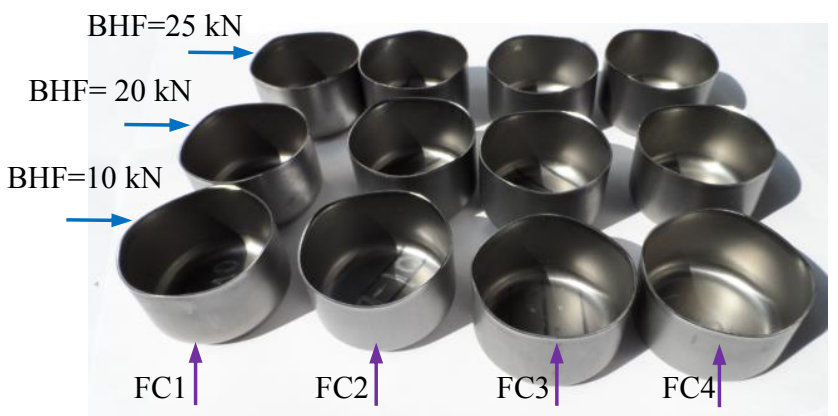

Fig. 2. Representative deep-drawn cups resulted from different combinations of friction conditions (FC) and blank-holding forces (BHF). 


\section{Finite element simulation of the deep-drawing process}

The aim of the finite element simulation of the deep-drawing process was to obtain the calibration diagrams. A calibration diagram consists in a set of deep-drawing force - punch displacement curves obtained using different values of the friction coefficient. By overlapping the experimental deep-drawing force - punch displacement curves on the calibration diagram, the friction coefficient for each friction condition can be estimated. Three values of the friction coefficient $(0.10,0.15$ and 0.20$)$ and three levels of the blankholding force $(10,20$ and $25 \mathrm{kN})$ were considered to obtain the calibration diagrams.

The Dynaform finite element software [10] was used for simulating the deep-drawing process. Figure 3 shows the FE model before and after generating the mesh. The FE model includes: punch (1), blank holder (2), blank (3) and die (4). The blank was modeled as a deformable body using shell elements with an average size of $1.5 \mathrm{~mm}$. The tools were modeled as rigid bodies. Swift's hardening law defined by (Eq. 1) was used to model the hardening of the blank and Barlat' 89 yield criterion was chosen to describe the yield surface.

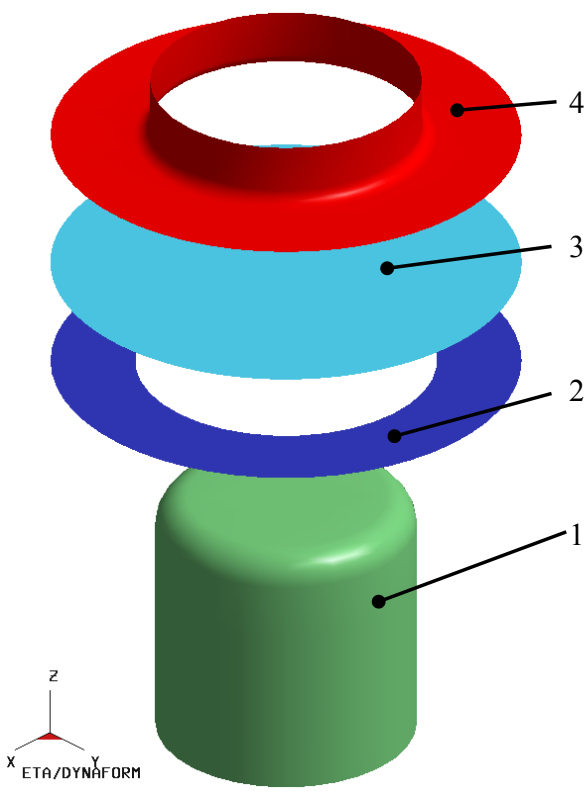

a)

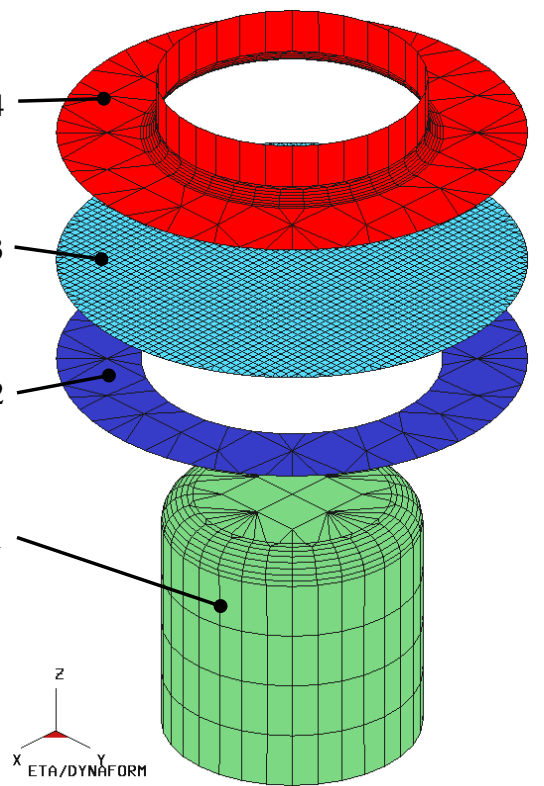

b)

Fig. 3. FE model of the deep-drawing test: a) and b) before and after meshing; 1 - punch; 2 - blank holder; 3 - blank; 4 - die.

\section{Results}

\subsection{Variation of the deep-drawing force under different friction conditions}

Figure 4 shows the deep-drawing force versus punch stroke curves corresponding to four friction conditions at the tool-blank interface and three levels of the blank-holding force considered in this study. From this figure one may see that, in all cases, the deep-drawing force increases when the punch moves up to about $15 \mathrm{~mm}$, where the maximum force is reached, after which the force begins to decrease. 

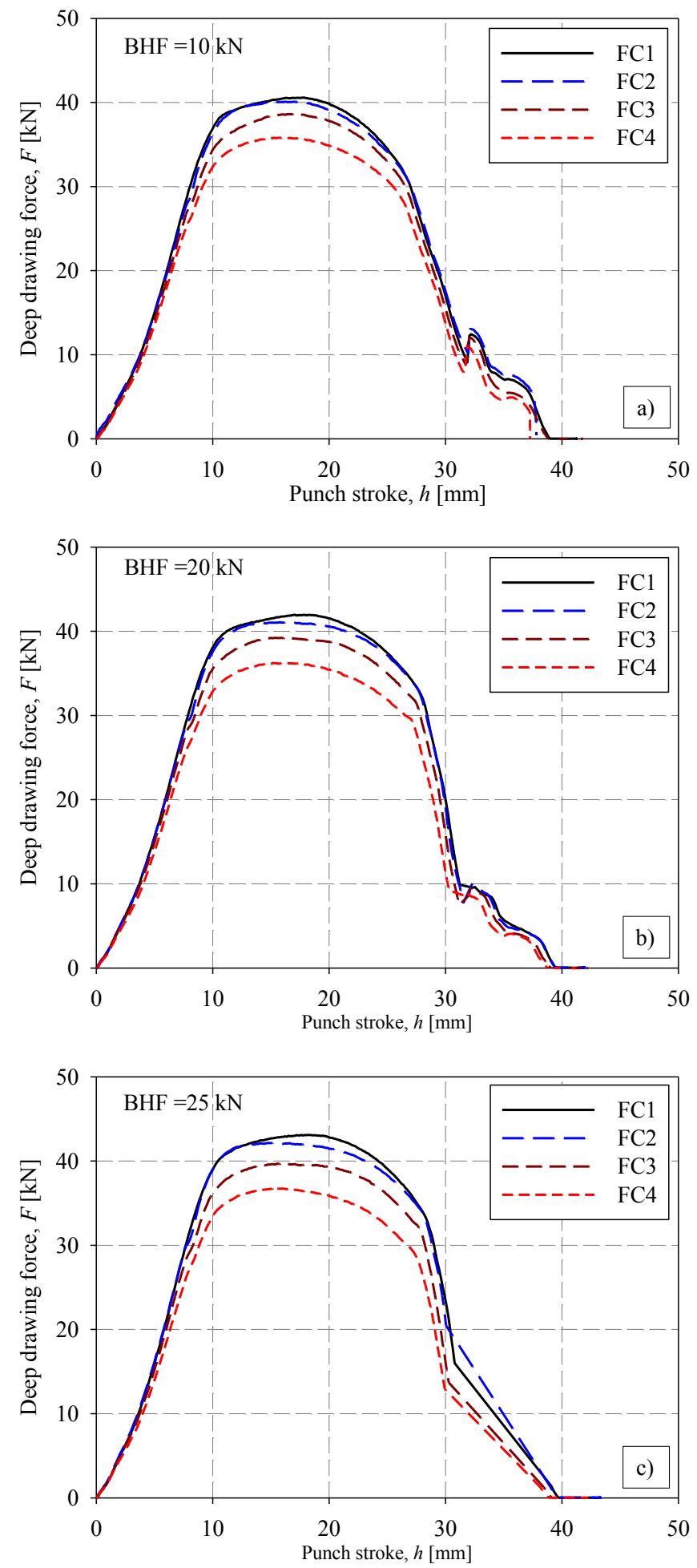

Fig. 4. Variation of the deep-drawing force under four friction conditions (FC) described in $\S 2.3$ and three levels of the blank-holding force (BHF). 
When the blank-holding force is low (BHF $=10 \mathrm{kN}$, Fig. 4a), the evolution of the deepdrawing force shows a slight increase towards the end of the punch stoke (at about $33 \mathrm{~mm}$ punch stoke). This increase can be caused by wrinkles that are unfolded when the drawn cup passes through the cylindrical cavity of the die. When the blank-holding force is high $(\mathrm{BHF}=25 \mathrm{kN}$, Fig. 4c), wrinkles do not occur and the local increase in the deep-drawing force is not visible. This evolution of the deep-drawing force during the forming process is consistent with the data reported in the literature [11].

One may also observe in these diagrams that, for all levels of the blank-holding force, the higher deep-drawing force occurs in the case of friction condition FC1, when no lubricant at the blank/tool interface was used. The force decreases in the other friction conditions in the following order: FC2 (hydraulic oil), FC3 (lithium-base grease) and FC4 (animal fat).

In order to quantitatively study the variation of the deep-drawing force under different friction conditions, the maximum deep-drawing force $\left(\mathrm{F}_{\max }\right)$ was plotted against the blankholding force (BHF) for all four friction conditions, as shown in Figure 5.

One may observe in Figure 5 that the maximum deep-drawing force is most sensitive to the change in the blank-holding force, when no lubricant is used at the blank/tool interface (friction condition FC1). In this case, when the blank-holding force is increased from 10 to $25 \mathrm{kN}$, the maximum deep-drawing force increases from 40.55 to $43.09 \mathrm{kN}$; this means an increase of $2.53 \mathrm{kN}$ in the maximum force. In the order of decreasing in sensitivity of the $\mathrm{F}_{\max }$ to the change in the blank-holding force, follow the cases: FC2; FC3 and FC4. In FC2 and $\mathrm{FC} 3$ cases, when BHF increases from 10 to $25 \mathrm{kN}$, the maximum deep-drawing force increases with 2.05 and $1.08 \mathrm{kN}$, respectively.

$\mathrm{F}_{\max }$ is less sensitive to the variation of the blank-holding force, when animal fat is used as lubricant (friction condition FC4). In this case, the increase of the blank-holding force from 10 to $25 \mathrm{kN}$ implies an increase in the maximum deep-drawing force from $35.81 \mathrm{kN}$ to $36.74 \mathrm{kN}$, which means an increase of $0.93 \mathrm{kN}$.
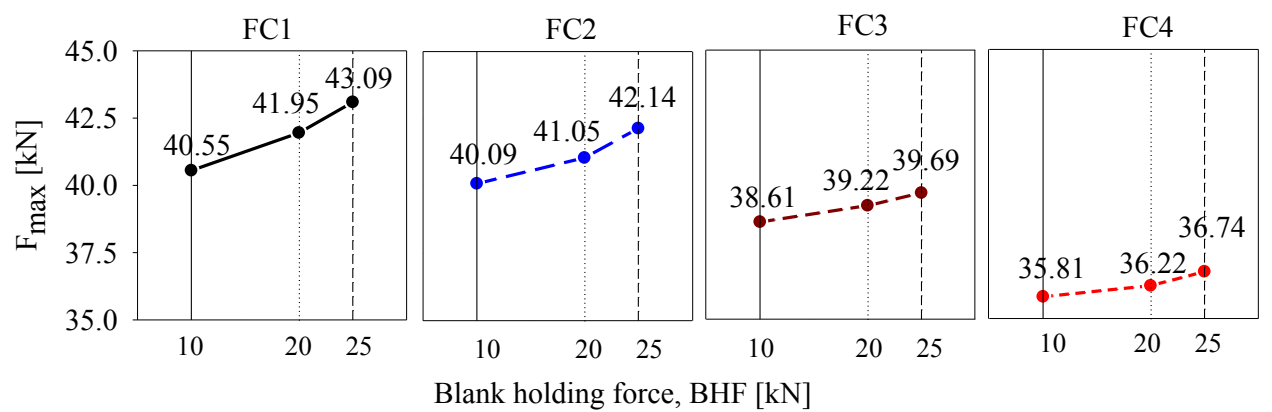

Fig. 5. Maximum deep-drawing force for three levels of the blank-holding force and different friction conditions (FC) described in $\S 2.3$.

\subsection{Estimation of the friction coefficient}

Figure 6 shows the calibration curves generated by FE simulation of the deep-drawing process using three different values of the friction coefficient $(\mu)$ and three levels of the blank-holding force. The experimental deep-drawing force vs punch stroke curves overlapped on these diagrams allow estimating the friction coefficient corresponding to each friction condition. One may deduce from Figure 6 that in the case of deep-drawing without lubricant (case FC1) the friction coefficient exhibits a value greater than 0.2 . A friction coefficient slightly above 0.2 was obtained in the case of hydraulic oil (case FC2). The friction coefficient for the lithium-based grease lubricant (case FC3) lies between 0.15 and 0.2. A friction coefficient between 0.1 and 0.15 was obtained for animal fat (case FC4). 

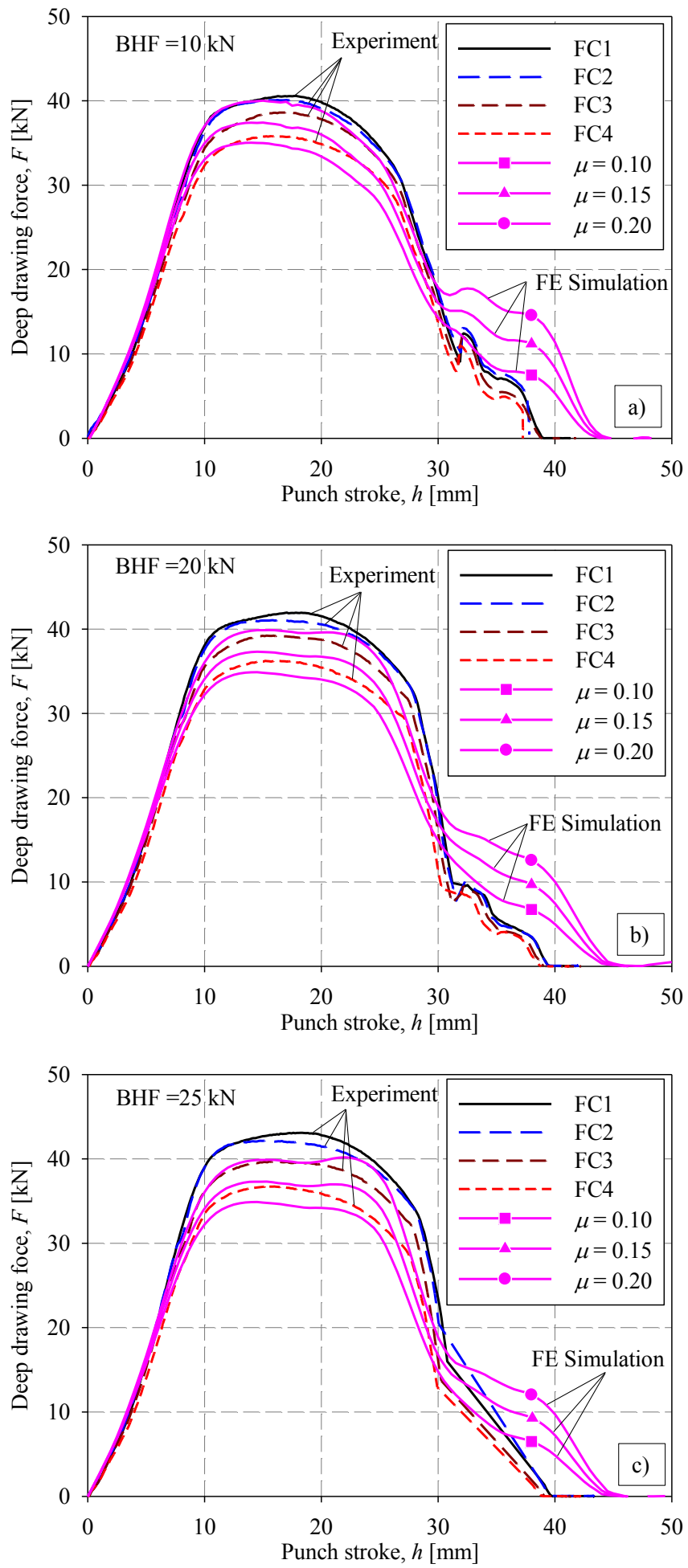

Fig. 6. Calibration of the friction coefficient by overlapping FE simulation with experimental results. 


\section{Conclusions}

The effect of friction conditions combined with the intensity of blank-holding in the deepdrawing process of cylindrical cups was investigated by experiments and Finite Element simulation. Based on the results of this paper, the following conclusions can be formulated:

1) The drawing force is significantly affected by all friction conditions considered in this study. The drawing force increases in the following sequence of lubricants used: animal fat, lithium-base lubricant, hydraulic oil. As expected, the higher drawing force was found in the case of dry deep-drawing.

2) The drawing force is less sensitive to the changes in the blank-holding force when animal fat was used as a lubricant; the sensitivity increases when lithium-based lubricant, hydraulic oil and dry deep-drawing was used.

3) The estimated values of the friction coefficients are as follows: a friction coefficient between 0.10 and 0.15 corresponds to animal fat; the friction coefficient for the lithiumbased lubricant lies between 0.15 and 0.20 ; a higher friction coefficient, very close to 0.20 , was obtained for hydraulic oil; the case of dry deep-drawing corresponds to a friction coefficient higher than 0.20 .

\section{References}

1. M. A. Ahmetoglu, A. Coremans, G. L. Kinzel, T. Altan, SAE Technical Paper No. 930287 (1993)

2. A. R. Padmanabhan, M.C. Oliveira, J.L. Alves, L.F. Menezes, Finite Elem. Anal. Des. 43, 1062 (2007)

3. S. Raju, G. Ganesan, R. Karthikeyan, Trans. Nonferrous Met. Soc. China 201856 (2010)

4. M. T. Browne, M. T. Hillery, J. Mater. Process. Technol. 13664 (2003)

5. M. Dilmec, M. Arap, Int. J. Adv. Manuf. Technol. 86747 (2016)

6. H. Kim, J. H. Sung, R. Sivakumar, T. Altan, Int. J. Mach. Tools Manuf. 472120 (2007)

7. H. Kim, T. Altan, Q. Yan, J. Mater. Process. Technol. 2094122 (2009)

8. S. Subramonian, N. Kardes, Y. Demiralp, M. Jurich, T. Altan, J. Manuf. Sci. Eng. 133 061001 (2011)

9. L. Ju, T. Mao, J. Malpica, T. Altan, J. Manuf. Sci. Eng. 133051010 (2015)

10. eta/DYNAFORM, User's Manual (Engineering Technology Associates, 2010)

11. L. Lăzărescu, I. Nicodim, D. Banabic, Key Eng. Mater. 63933 (2015) 